\title{
Zulassungssteuerung nur auf Basis von Qualitätskriterien
}

\author{
Jürg Schlup \\ Dr. med., Präsident der FMH
}

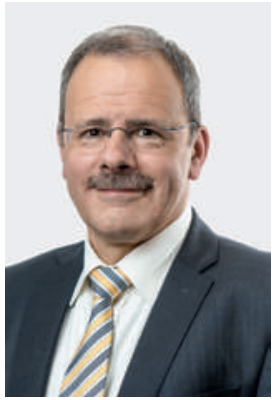

Als der Bundesrat 2002 vor dem Hintergrund des Inkrafttretens des Personenfreizügigkeitsabkommens einen Zulassungsstopp für praxisambulant tätige Ärztinnen und Ärzte verfügte, galt dieser als vorläufig und befristet. Dennoch wurde er mit den nachfolgenden drei Verlängerungen zum Dauerzustand.

Immerhin gelang es jedoch 2013 erstmals die Zulassung, wie von der FMH gefordert, an Qualitätskriterien zu binden. Eine gute Kenntnis unserer Gesundheitsversorgung, operationalisiert über eine mindestens dreijährige Tätigkeit an einer anerkannten schweizerischen Weiterbildungsstätte, wurde zum zentralen Kriterium. Nicht zuletzt weil sich dieser Qualitätsfokus in den letzten Jahren als Kompromiss bewährt hatte, schien diese Regelung geeignet zur Verstetigung bis die Vorlage im Dezember 2015 überraschend mit 97 zu 96 Stimmen im Nationalrat scheiterte. Es ist kein Geheimnis, dass viele der parlamentarischen Gegner Sympathien für einen Gegenvorschlag haben, der die Aufhebung der freien Arztwahl oberhalb einer bundesrätlich festgelegten, schweizweit einheitlichen Ärztedichte fordert (13.3265 Motion Stahl). In der Innerschweiz, wo die Ärztedichte von jeher deutlich geringer ist als in Genf oder Basel, würde damit wohl nie die Vertragsfreiheit eingeführt, in den genannten Städten würde sie hingegen dauerhaft etabliert.

Die FMH bietet weiterhin Hand für Lösungen, die auf Qualitätskriterien basieren.

Die Gründe gegen die Vertragsfreiheit liegen auf der Hand: Die Krankenversicherung würde für ihre Versicherten ungefragt die Arztwahl einschränken. Wo für Patientinnen* primär die Versorgungsqualität zählt, sind es für die Kasse die Kosten. Kostengünstig behandelnde Ärztinnen würden bevorzugt, die ambulante Behandlung "teurer» Patienten, beispielsweise chronisch Erkrankter, würde unattraktiv. Der gesetzeswidrige Ausschluss aller Doppeltitelträger von Listenmodellen durch einige Kassen zeigt, wohin dann die Reise ginge: nicht in Richtung Qualität.

Die vom Nationalrat unterstützte Vertragsfreiheit

lehnte der Ständerat Mitte Januar deutlich ab, legte aber gleichzeitig auch ein Postulat mit klaren Forderungen vor: Der Bundesrat solle unter Einbezug der wichtigen Akteure verschiedene Steuerungsoptionen für praxis- und spitalambulanten Bereich erarbeiten. Neben der Festlegung von Ober- und Untergrenzen der Ärztedichte durch den Bund sollen demnach auch Vertragsfreiheit und differenzierte Tarife als Möglichkeiten geprüft werden. Letzteres, also die vertiefte Prüfung differenzierter Taxpunktwerte, ist auch Gegenstand einer neuen Motion aus dem Nationalrat. Die Gesundheitskommissionen beider Parlamentskammern wollen demnach offenbar noch einmal über die Bücher gehen und verschiedenste Regelungen erwägen.

\section{Eine befristete Verlängerung der geltenden} Regelung kann die Voraussetzung für eine vernünftige und ausgewogene Lösung schaffen.

Ein solches Vorgehen erfordert jedoch Zeit: Zeit, die sich mittels einer weiteren, neuen parlamentarischen Initiative gewinnen liesse, die eine dreijährige Verlängerung der aktuellen Regelung fordert. Diese Initiative würde verhindern, dass die aktuelle Zulassungssteuerung am 30. Juni 2016 ersatzlos ausläuft, und könnte den drohenden Aktionismus der unter starkem Druck stehenden Politik in konstruktive Bahnen lenken. Dieser Zeitgewinn wäre auch sinnvoll, um die Auswirkungen der Masseneinwanderungsinitiative mit ihren Fachkräftekontingentierungen ab 2017 in einer Nachfolgeregelung hinreichend berücksichtigen zu können. Denn wo nicht genug Ärztinnen ausgebildet werden, beeinflusst die Einwanderungspolitik die Gesundheitsversorgung entscheidender als die Zulassungssteuerung.

Für die FMH ist die Verlängerung der aktuell gültigen, auf Qualitätskriterien beruhenden Zulassungssteuerung in unveränderter Form bis 2019 ein gangbarer Weg. Und auch für längerfristige Lösungen, die auf Qualitätskriterien basieren, wie zum Beispiel Weiterbildungsdauer oder Sprachkompetenz, wird die FMH Hand bieten. Eine Einschränkung der freien Arztwahl lehnen wir hingegen klar ab. 